\title{
The effect of non-traditional cooling on dog sperm cryosurvival and ability to perform the acrosome reaction
}

\author{
Luis D. Ortega-Morales, Alicia Alcantar-Rodriguez, Maria C. Espejel, Alfredo Medrano*
}

\begin{abstract}
The objective of this study was to assess cryosurvival, plasma membrane fluidity, and capability of cryopreserved $\operatorname{dog}$ (Canis lupus familiaris) spermatozoa, cooled to $-5{ }^{\circ} \mathrm{C}$ before freezing, to perform the acrosome reaction under the effect of progesterone and calcium ionophore. In the first experiment, fresh spermatozoa diluted in Tyrode's medium plus albumin, lactate, and pyruvate (TALP) were incubated at $38{ }^{\circ} \mathrm{C}$ in $5 \% \mathrm{CO}_{2}$ in air, with progesterone or calcium ionophore added at 2,4 , and $6 \mathrm{~h}$ after incubation and sampled $30 \mathrm{~min}$ later to assess the acrosome reaction. In the second experiment, diluted sperm were packaged in plastic straws, cooled to either $+5^{\circ} \mathrm{C}$ or $-5^{\circ} \mathrm{C}$ and cryopreserved. Progressive motility, plasma membrane integrity and fluidity, capacitation status and acrosome integrity were assessed before and after freeze-thawing. After thawing, sperm were assessed, resuspended in TALP and incubated to assess the acrosome reaction. Parameters for sperm cryosurvival were similar in sperm cooled to either $+5^{\circ} \mathrm{C}$ or $-5{ }^{\circ} \mathrm{C}$, except in the percentage of hyper-fluid membranes which was lower $(P<0.05)$ in sperm cooled to $-5{ }^{\circ} \mathrm{C}$. There were no differences in the percentages of frozen-thawed spermatozoa with acrosome reaction, induced by progesterone or calcium ionophore, between cooling treatments. In conclusion, cooling of dog spermatozoa to $-5^{\circ} \mathrm{C}$ did not improve sperm cryosurvival but had a positive effect on plasma membrane fluidity.

Key words: dog semen, freeze-thawing, progesterone, calcium ionophore, membrane fluidity.
\end{abstract}

\section{INTRODUCTION}

Sperm cryopreservation results in different advantages in dog breeding, such as the movement of genetic material among different geographic regions, thus increasing genetic variability and the use of the best males (Eilts 2005). However, cryopreservation invariably reduces the fertilising capacity of spermatozoa (Watson 1995), therefore, the research aiming to elucidate the mechanisms responsible for damage to sperm physiology caused by low temperatures is of great importance (Eilts 2005). A phenomenon that sperm have to face during cryopreservation is the phase transition of lipids that comprise the plasma membrane. As the temperature decreases, the lipids progressively change from a liquid-crystalline phase to a gel phase. Consequently the membrane loses elasticity (Watson 1995). Most lipids undergo this change at temperatures above zero degrees, however, there is evidence that some additional phase transitions could occur below zero degrees (Crowe et al 1989). The lipid composition of the plasma membrane (cholesterol and unsaturated fatty acids) is directly related to the motility of the sperm and the fluidity of the membrane; the presence of unsaturated fatty acids gives the membrane greater fluidity. Lucio et al (2017) have reported the presence of both saturated (palmitic and stearic) and unsaturated fatty acids (arachidonic and oleic) in dog spermatozoa.

Received: 14.06 .2018

Accepted: 20.11.2018.

Multidisciplinary Research Unit (L2), Faculty of Superior Studies Cuautitlan, National Autonomous University of Mexico, Cuautitlan, Mexico.

*Corresponding author: A Medrano; amedrano@unam.mx.
In addition, freezing affects the physical states of membrane lipids due to changes in the hydration level. Membrane phase transition may cause different effects on the membrane conformational disorder in the frozen state when the ice nucleation occurs at different sub-zero temperatures (Balasubramanian et al 2009).

Thus, spermatozoa are subjected to volume changes (i.e., intracellular water flow for ice formation), while their plasma membrane is suffering conformational rearrangements -changes in fluidity-due to lipid phase transitions. One approach that could assist the sperm plasma membrane to manage those stressors in order to maintain its viability is to extend the cooling of spermatozoa to sub-zero temperatures $\left(-5^{\circ} \mathrm{C}\right)$ before freezing. In this way, the occurrence of severe changes in plasma membrane fluidity could be reduced. Some researchers have been exploring the effect of cooling to sub-zero temperatures on sperm cryosurvival (Garzon-Perez et al 2010, Contreras-Mendez and Medrano 2016, Alcantar-Rodriguez and Medrano 2017). However, they have obtained either positive or null effects on sperm cryosurvival.

Assessment of the sperm fertilising capacity by measuring the ability of the cell to suffer the acrosome reaction is considered a valuable test in fresh and cryopreserved spermatozoa (Graham and Foote 1987, Whitfield and Parkinson 1992). The objective of this work was to test further the effect of cooling to $-5{ }^{\circ} \mathrm{C}$ before freezing on dog sperm cryosurvival, plasma membrane fluidity and the sperm capability to carry out the acrosome reaction, comparatively employing 2 inductors: progesterone $\left(\mathrm{P}_{4}\right)$ and calcium ionophore (CI). In this work, 2 cooling protocols were compared by inducing the acrosome reaction on cryopreserved dog spermatozoa as a measure of the in vitro fertilising capacity of spermatozoa. 


\section{MATERIAL AND METHODS}

All experiments comply with the guidelines of the Institutional Subcommittee for the Care of Animals in Experimentation from the National Autonomous University of Mexico (Faculty of Superior Studies, Cuautitlan). Semen assessment and cryopreservation were carried out in the laboratory of Animal Reproduction (UIM-FESC), National Autonomous University of Mexico.

\section{SEMEN COLLECTION AND PROCESSING}

Semen was collected by manual stimulation from 3 dogs (first experiment, 6 ejaculates per male: 1 Shih-tzu and 2 mixed races, 3 to 5 years of age) and 5 dogs (second experiment, 3 ejaculates per male: 3 Belgian and 2 German Shepherd, 2 to 8 years of age) once a week from the same male, from January to August $2016\left(20^{\circ} \mathrm{N}\right)$. Only 1 ejaculate from the corresponding dog was collected per each day of work, and each individual ejaculate was treated separately. Only ejaculates showing at least $80 \%$ progressive motility and $85 \%$ viability were included in these experiments.

Each ejaculate was diluted 1:1 (v/v) in a Tris/citric acid/glucose solution (TRIS $198.2 \mathrm{mM}$, citric acid 72.9 $\mathrm{mM}$, glucose $8.9 \mathrm{mM}$, and kanamycin $0.83 \mathrm{mg} / \mathrm{ml}$ ) to be transported at approximately $28^{\circ} \mathrm{C}$. Semen arrived at the laboratory within $30 \mathrm{~min}$ of collection.

\section{SEMEN ASSESSMENT}

Immediately after collection, semen was macroscopically assessed for volume, colour, consistency and presence of strange materials (hair, blood). Once in the laboratory, semen in the transport solution was left at room temperature $\left(18-23^{\circ} \mathrm{C}\right)$ for $45 \mathrm{~min}$ to adjust, then an aliquot was taken and diluted 1:6 (v/v) in phosphate-buffered saline PBS at $34{ }^{\circ} \mathrm{C}$. Ten min later, sperm were microscopically assessed for progressive motility, sperm concentration, viability, sperm morphology, plasma membrane integrity, acrosome integrity, capacitation status and plasma membrane fluidity.

Progressive motility, the percentage of sperm showing progressive and linear movement was subjectively assessed under light microscopy (Leica DMLS) using the $20 \mathrm{x}$ objective.

Sperm concentration was estimated from a 1:200 dilution (semen: formaldehyde saline solution v/v) with the aid of the Neubauer chamber using the 40x objective.

Viability was assessed by counting live (non-stained) and dead (stained) spermatozoa (at least 200 hundred) in smears stained with eosin-nigrosine using the $100 \mathrm{x}$ objective. Sperm morphology was assessed by counting normal and abnormal (primary and secondary) cells (at least 200 hundred) in smears stained with eosin-nigrosine using the 100x objective (Feldman and Nelson 1996).
Plasma membrane integrity was assessed as follows: $50 \mu$ of diluted spermatozoa (in PBS $1+5 \mathrm{v} / \mathrm{v}$ ) were added to $5 \mu \mathrm{l}$ of SYBR14 (100 nmol/L) and mixed. Immediately, $5 \mu \mathrm{l}$ of propidium iodide (PI, $12 \mu \mathrm{mol} / \mathrm{L}$ ) was added and mixed again for $10 \mathrm{~s}$. Finally, $5 \mu \mathrm{l}$ of glutaraldehyde $(0.4 \%)$ was added to immobilise the spermatozoa (Garner and Johnson 1995). The percentage of live cells (SYBR14positive and PI-negative) was calculated after counting 200 spermatozoa under fluorescence microscopy (Leica DMLS) using the 100x objective.

Acrosome integrity was assessed as follows: diluted sperm were smeared on a slide and air-dried, and then cells were permeabilised in alcohol for $60 \mathrm{~min}$. Then, 50 $\mu \mathrm{l}$ of fluorescein-conjugated Pisum sativum agglutinin (PSA-FITC) lectin (L0770 Sigma St. Louis MO, USA) was spread on the slide and left in the dark for $10 \mathrm{~min}$. Immediately, the slide was gently washed with distilled water and air-dried (Medrano et al 2009). One drop of an antifade solution (DABCO $220 \mathrm{mM}$ in glycerol, (D-2522 Sigma St. Louis MO USA) was put on the slide, and a coverslip was positioned on top. The percentage of cells showing a smooth and well-defined acrosome was calculated after counting 200 spermatozoa under fluorescence microscopy using the 100x objective.

Capacitation status was assessed by the chlortetracycline (CTC) assay as follows: $100 \mu \mathrm{l}$ of diluted sperm (in PBS $1+5 \mathrm{v} / \mathrm{v})$ were added to $100 \mu \mathrm{l}$ of CTC solution ( $\mathrm{pH} 7.8)$, mixed for $30 \mathrm{~s}$ and $20 \mu \mathrm{l}$ of glutaraldehyde $(0.2 \%)$ were added to immobilise the sperm (Green and Watson, 2001). CTC-stained sperm were mixed $(1: 1 \mathrm{v} / \mathrm{v})$ with antifade solution on a slide, and a coverslip was positioned on top. Percentages of cells showing any of the CTC patterns were calculated after counting 200 spermatozoa under fluorescence microscopy using the 100x objective: F, with uniform fluorescence over the whole head (non-capacitated acrosome-intact spermatozoa); B, with fluorescence-free band in the post-acrosomal region (capacitated acrosome-intact spermatozoa); or AR, with almost no fluorescence over the whole head except for a band of fluorescence in the equatorial segment (acrosome-reacted spermatozoa) (Rota et al 1999).

To assess sperm plasma membrane fluidity, a Merocyanine 540 assay was carried out as follows: a stock solution of Merocyanine (5 mM) in dimethyl sulphoxide (DMSO, 154938 Sigma St. Louis MO, USA) was prepared and stored at room temperature $\left(23^{\circ} \mathrm{C}\right)$ protected from the light until use. Then, a working solution of Merocyanine $(40 \mu \mathrm{M})$ in PBS $(495 \mu \mathrm{L}$ PBS $+5 \mu \mathrm{L}$ Merocyanine $(5 \mathrm{mM})$ in DMSO) was freshly prepared before use. One hundred and forty microlitres of sperm in PBS were added to 10 $\mu \mathrm{L}$ of the Merocyanine working solution, mixed, and left for $1 \mathrm{~min}$ to interact. Then, $22 \mu \mathrm{L}$ of glutaraldehyde $(0.4 \%)$ were added to fix the sperm. One drop of this mix and 1 drop of antifade solution (DABCO $220 \mathrm{mM}$ in glycerol/PBS) were put on a warm glass slide, and a glass cover slide was positioned on top. Gentle pressure 
was applied to the cover slide, with the aid of absorbent paper to eliminate the excess liquid. Percentages of cells showing either of the Merocyanine patterns, opaque (low fluidity) or brilliant (high fluidity - high-binding cells), were calculated after counting 200 spermatozoa under fluorescence microscopy (Leica DMLS) using the 100x objective (Steckler et al 2015).

\section{EXPERIMENTAL DESIGN}

Experiment 1. Validation of the use of 2 inductors of the acrosome reaction on fresh-incubated dog spermatozoa. This experimental stage was carried out to identify the optimum incubation time for each of the inductors of the acrosome reaction to produce the highest proportion of acrosome-reacted spermatozoa. Fresh spermatozoa, diluted in Tyrode's medium plus albumin, lactate and pyruvate (TALP), were incubated during $6.5 \mathrm{~h}$, employing 2 inductors of the acrosome reaction: $\mathrm{CI}$ and progesterone (P4). Semen was collected, diluted and transported as mentioned. Immediately after adjustment at room temperature, diluted semen was centrifuged at $750 \mathrm{~g}$ for 5 min, supernatant was removed and TALP medium was added to reach $400 \times 10^{6} \mathrm{sperm} / \mathrm{ml}$. Sperm in TALP were further diluted to reach either $100 \times 10^{6} \mathrm{sperm} / \mathrm{ml}$ (for CI experiment) or $75 \times 10^{6} \mathrm{sperm} / \mathrm{ml}$ (for $\mathrm{P} 4$ experiment). Immediately, sperm suspension was split in aliquots of 200 $\mu \mathrm{l}$ each, which were incubated at $38^{\circ} \mathrm{C}$ in $5 \% \mathrm{CO} 2$ in air, and sampled when required. Either CI $(2.5 \mu \mathrm{M}$, SigmaAldrich, USA) in Tyrode's medium (Szász et al 2000) or P4 (10 $\mu \mathrm{g} / \mathrm{ml}$, Sigma-Aldrich, USA) in Tyrode's medium (Cheng et al 2005) were added at 2, 4 and $6 \mathrm{~h}$ of incubation and left for $30 \mathrm{~min}$ to interact before sampling. Progressive motility, plasma membrane integrity, capacitation status and acrosome integrity were assessed at 0, 2, 2.5, 4, 4.5, 6 and $6.5 \mathrm{~h}$ of incubation in the control and treated groups (figure 1).

Eighteen ejaculates from 3 dogs ( 6 from each male; 3 per each AR inductor) were used in this stage.

Experiment 2. Sperm cryopreservation and post-thawing incubation. This experimental stage was carried out to assess both sperm cryosurvival after cooling to 2 pre-freeze temperatures $\left(+5^{\circ} \mathrm{C}\right.$ vs. $\left.-5^{\circ} \mathrm{C}\right)$ and the capacity of frozen-thawed spermatozoa to perform the acrosome reaction employing calcium ionophore A23187 and progesterone (figure 2). Semen was collected, diluted and transported as previously mentioned. Immediately after adjustment at room temperature, diluted semen was centrifuged at 750 $\mathrm{g}$ for $5 \mathrm{~min}$, supernatant was removed and egg yolk-Tris (EYT) medium containing 3\% glycerol (Peña and Linde Forsberg 2000) was added to reach $400 \times 10^{6} \mathrm{sperm} / \mathrm{ml}$. Fifteen ejaculates ( 6 straws: 3 for each cooling temperature) from 5 dogs were used in this stage.

Diluted sperm were slowly cooled from $23{ }^{\circ} \mathrm{C}$ to $5{ }^{\circ} \mathrm{C}$ in approximately $2 \mathrm{~h}\left(0.17^{\circ} \mathrm{C} / \mathrm{min}\right)$. Then, EYT medium

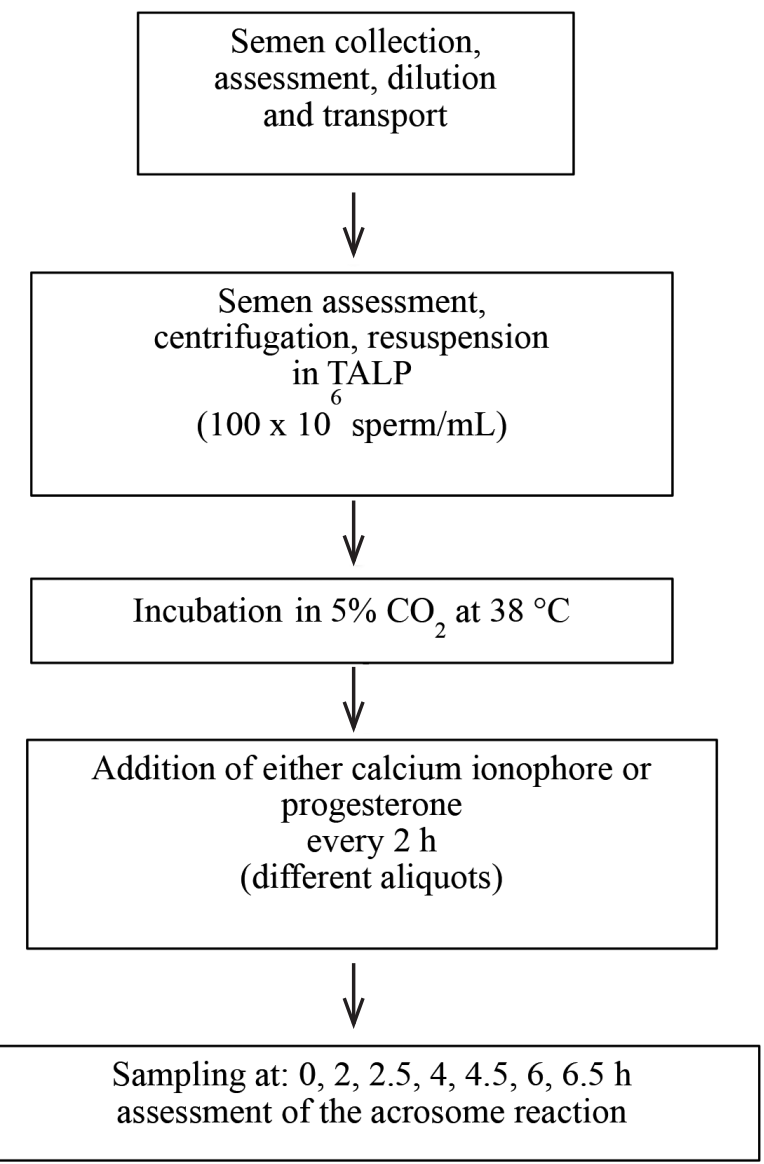

Figure 1. Flow chart of Experiment 1. Validation of the use of 2 inductors of the acrosome reaction on fresh-incubated dog spermatozoa.

containing $7 \%$ glycerol was added to reach a final concentration of $200 \times 10^{6}$ sperm $/ \mathrm{ml}$ and $5 \%$ glycerol, and diluted sperm was packaged into $0.5 \mathrm{ml}$ plastic straws, which remained in equilibrium for $30 \mathrm{~min}$ before freezing. Half of the straws at $+5{ }^{\circ} \mathrm{C}$ (control) were frozen in $4 \mathrm{~cm}$ of nitrogen vapour over liquid nitrogen levels for $15 \mathrm{~min}$ and stored in liquid nitrogen. The other half at $+5{ }^{\circ} \mathrm{C}$ were further cooled to $-5^{\circ} \mathrm{C}$ at approximately $0.04^{\circ} \mathrm{C} / \mathrm{min}$ (experimental), frozen and stored as mentioned. To cool the straws to sub-zero temperatures, an insulated box filled with crushed saline ice $(10 \% \mathrm{w} / \mathrm{v})$ at $-12{ }^{\circ} \mathrm{C}$ was used. This method had been previously validated in our laboratory (Alcantar-Rodriguez and Medrano 2017). Temperature was carefully monitored with the aid of a thermocouple (HANNA Instruments, USA) positioned inside a monitor straw containing EYT diluent (5\% glycerol). Readouts were stored in a computer using a special software (HANNA Instruments, USA).

Thawing was performed by immersing straws ( 3 per treatment) in water at $38^{\circ} \mathrm{C}$ for $30 \mathrm{~s}$. The content of each straw was poured in dry tubes into the water bath (4.5 1 volume). Each straw was assessed separately. Variables 

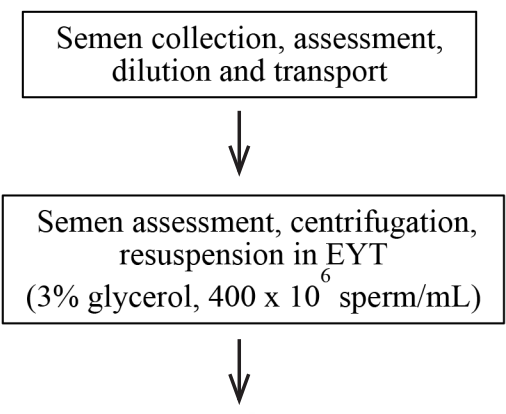

Cooling to $5{ }^{\circ} \mathrm{C}$, addition of EYT (7\% glycerol, $200 \times 10^{6}$ sperm $\left./ \mathrm{mL}\right)$ packaging in $0.5 \mathrm{~mL}$ straws

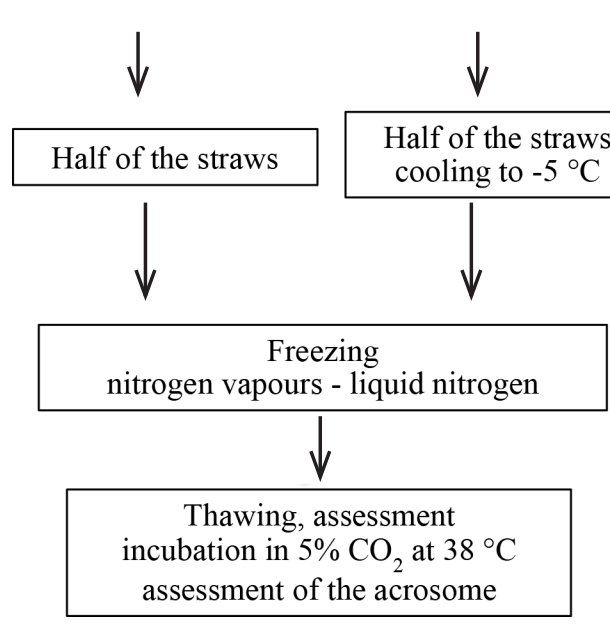

Figure 2. Flow chart of Exeriment 2. Sperm cryopreservation and post-thawing incubation.

were progressive motility, viability, plasma membrane integrity, acrosome integrity, capacitation status, and plasma membrane fluidity.

Induction of the acrosome reaction on cryopreserved dog spermatozoa. Straws (3 per treatment) were thawed, and sperm was assessed as mentioned. Then, diluted sperm from the 3 straws were pooled and centrifuged at $300 \mathrm{~g}$ for 4 min, supernatant was removed and the pellet was resuspended in TALP to reach $75 \times 10^{6} \mathrm{sperm} / \mathrm{ml}$. Sperm suspention was split into 5 aliquots of $200 \mu \mathrm{l}$ each that were incubated at $38{ }^{\circ} \mathrm{C}$ in $5 \% \mathrm{CO}_{2}$ in air, and sampled at (i) $0 \mathrm{~h}$ - control, (ii) $4 \mathrm{~h}$ - control and (iii) $4: 30 \mathrm{~h}$ - control, $\mathrm{CI}$ and $\mathrm{P}_{4}$. CI and $\mathrm{P}_{4}$ were added after $4 \mathrm{~h}$ of incubation and left for $30 \mathrm{~min}$ to interact with the sperm. Then, sperm acrosome and plasma membrane integrity were assessed.

\section{STATISTICAL ANALYSIS}

Data from the first experiment (incubation times and the effect of AR inductors) was analysed using the Friedman test of analysis of variance (ANOVA, repeated measures), Wilcoxon matched pair test and the "t" test (Snedecor and
Cochran 1989). Data from the second experiment (sperm cryopreservation and post-thawing incubation) was analysed by (i) ANOVA (fresh semen variables), with variables expressed in percentages arcsine-transformed to normalise them, (ii) " $\mathrm{t}$ " test (frozen-thawed sperm, cooled before freezing at either +5 or $-5^{\circ} \mathrm{C}$ ) and (iii) Friedman ANOVA (incubation times of frozen-thawed sperm). To compare treatments (Control, $\mathrm{CI}$, and $\mathrm{P}_{4}$ ) at 4:30 h of incubation, ANOVA and Tukey tests were used as well as the software SPSS v15.0 (2006, Chicago, USA).CITAR ATRAS

\section{RESULTS}

EXPERIMENT 1.VALIDATION OF THE USE OF 2 INDUCTORS OF THE ACROSOME REACTION ON FRESH-INCUBATED DOG SPERMATOZOA

Stage 1. Calcium ionophore A23187 (CI). Sperm motility decreased constantly as incubation progressed. At 2.5 and $6.5 \mathrm{~h}$ of incubation, there were no differences between the control and CI, however, at $4.5 \mathrm{~h}$ of incubation they were different $(P<0.05)$ (figure 3$)$. The number of plasma membrane-intact spermatozoa decreased constantly as incubation progressed; there were no differences between the control and $\mathrm{CI}$ at any of the incubation times (figure 3). The number of acrosome-intact spermatozoa decreased as incubation progressed; there were no differences between 4 and $4.5 \mathrm{~h}$ as well as between 6 and $6.5 \mathrm{~h}$. At 2.5, 4.5 and $6.5 \mathrm{~h}$ of incubation, there were differences $(P<0.05)$ between the control and CI 3 (figure 3).

The number of non-capacitated, acrosome-intact spermatozoa (CTC, F Pattern) decreased constantly as incubation progressed. At 2.5 and $4.5 \mathrm{~h}$ of incubation, there were differences $(P<0.05)$ between the control and $\mathrm{CI}$, however, at $6.5 \mathrm{~h}$ of incubation, there was no difference (figure 4). Number of capacitated, acrosome-intact spermatozoa (CTC, B Pattern) increased constantly as incubation progressed, reaching top values at 4 and $4.5 \mathrm{~h}$ and decreasing at $6.5 \mathrm{~h}$ of incubation $(P<0.05)$. At $2.5 \mathrm{~h}$ of incubation, there was no difference between the control and CI, however, at 4.5 and $6.5 \mathrm{~h}$ of incubation, they were different $(P<0.05)$ (figure 4$)$. The number of acrosome-reacted spermatozoa (CTC, AR Pattern) increased constantly as incubation progressed. At 2.5, 4.5 and 6.5 $\mathrm{h}$ of incubation, there were differences $(P<0.05)$ between the control and CI (figure 4).

Stage 2. Progesterone (P4). Sperm motility decreased constantly as incubation progressed. At 2.5 and $6.5 \mathrm{~h}$ of incubation, and there were no differences between the control and $\mathrm{P} 4$, however, at $4.5 \mathrm{~h}$ of incubation they were different $(P<0.05)$ (figure 5). The number of plasma membrane-intact spermatozoa decreased constantly as incubation progressed; there were no differences between the control and $\mathrm{P}_{4}$ at any of the incubation times (figure 5). The number of acrosome-intact spermatozoa decreased as 

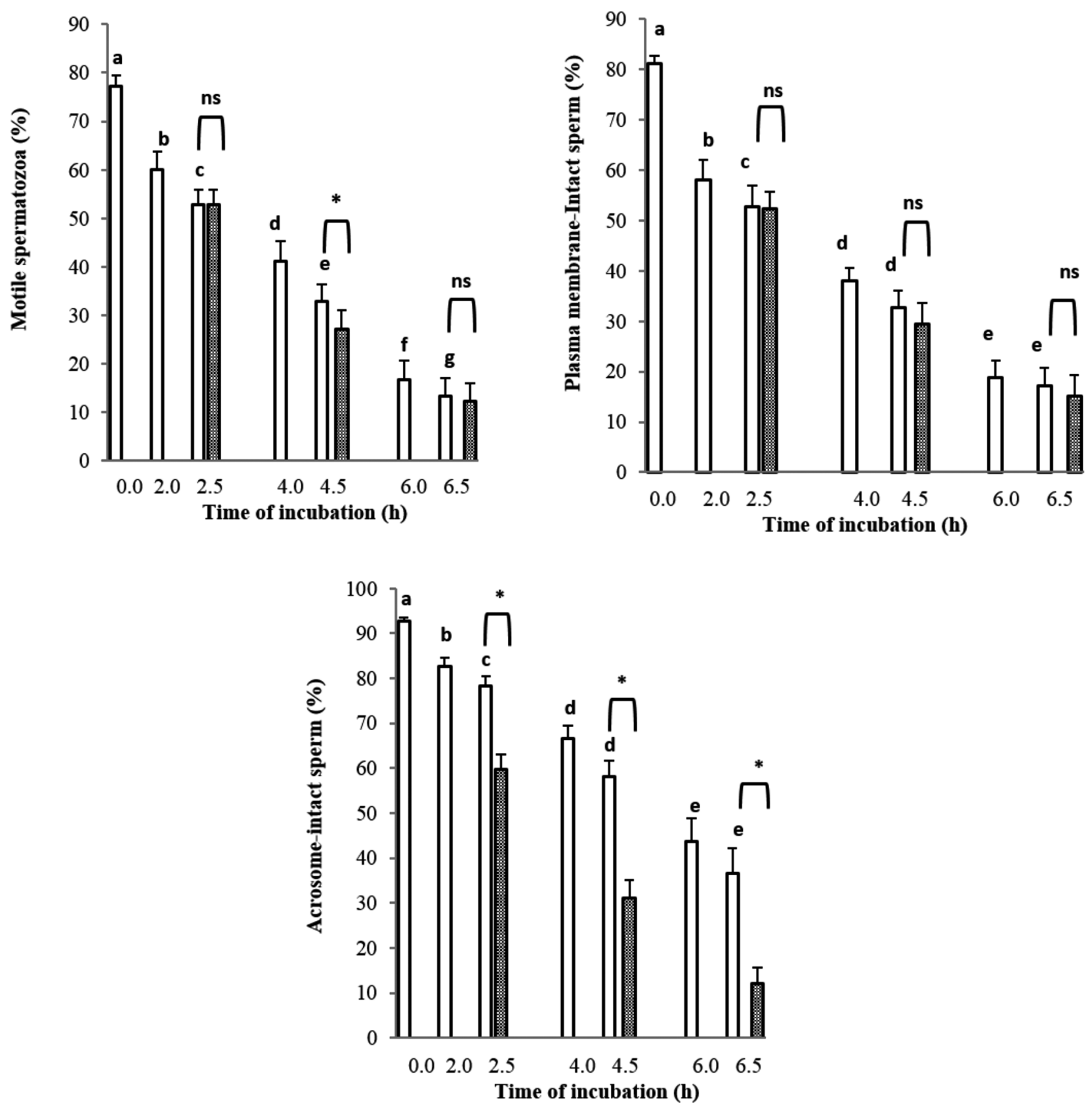

Figure 3. Motile, plasma membrane-intact, and acrosome-intact dog spermatozoa incubated at $37^{\circ} \mathrm{C}$ during $6.5 \mathrm{~h}$ under the effect of calcium ionophore. Values are means + SEM.

Control: open bars (a-g), calcium ionophore: shadowed bars.

Control vs calcium ionophore: $* P<0.05$, ns $=$ non significant.

incubation progressed. At 2.5, 4.5 and $6.5 \mathrm{~h}$ of incubation, there were differences $(P<0.05)$ between the control and $\mathrm{P}_{4}$ (figure 5).

Number of non-capacitated, acrosome-intact spermatozoa (CTC, F Pattern) decreased constantly as incubation progressed; there were significant differences $(P<0.05)$ between the control and $\mathrm{P}_{4}$ at 2.5, 4.5 and $6.5 \mathrm{~h}$ of incubation (figure 6). The number of capacitated, acrosome-intact spermatozoa (CTC, B Pattern) increased constantly as incubation progressed, reaching top values at 4 and $4.5 \mathrm{~h}$ and decreasing at $6.5 \mathrm{~h}$ of incubation $(P<0.05)$. At $2.5 \mathrm{~h}$ of incubation, there was no difference between the control and $\mathrm{P}_{4}$; however, at 4.5 and $6.5 \mathrm{~h}$ of incubation, they were different $(P<0.05)$ (figure 6). The number of acrosome-reacted spermatozoa (CTC, AR Pattern) increased constantly as incubation progressed. At 2.5, 4.5 and 6.5 $\mathrm{h}$ of incubation, there were differences $(P<0.05)$ between the control and $\mathrm{P}_{4}$ (figure 6). 

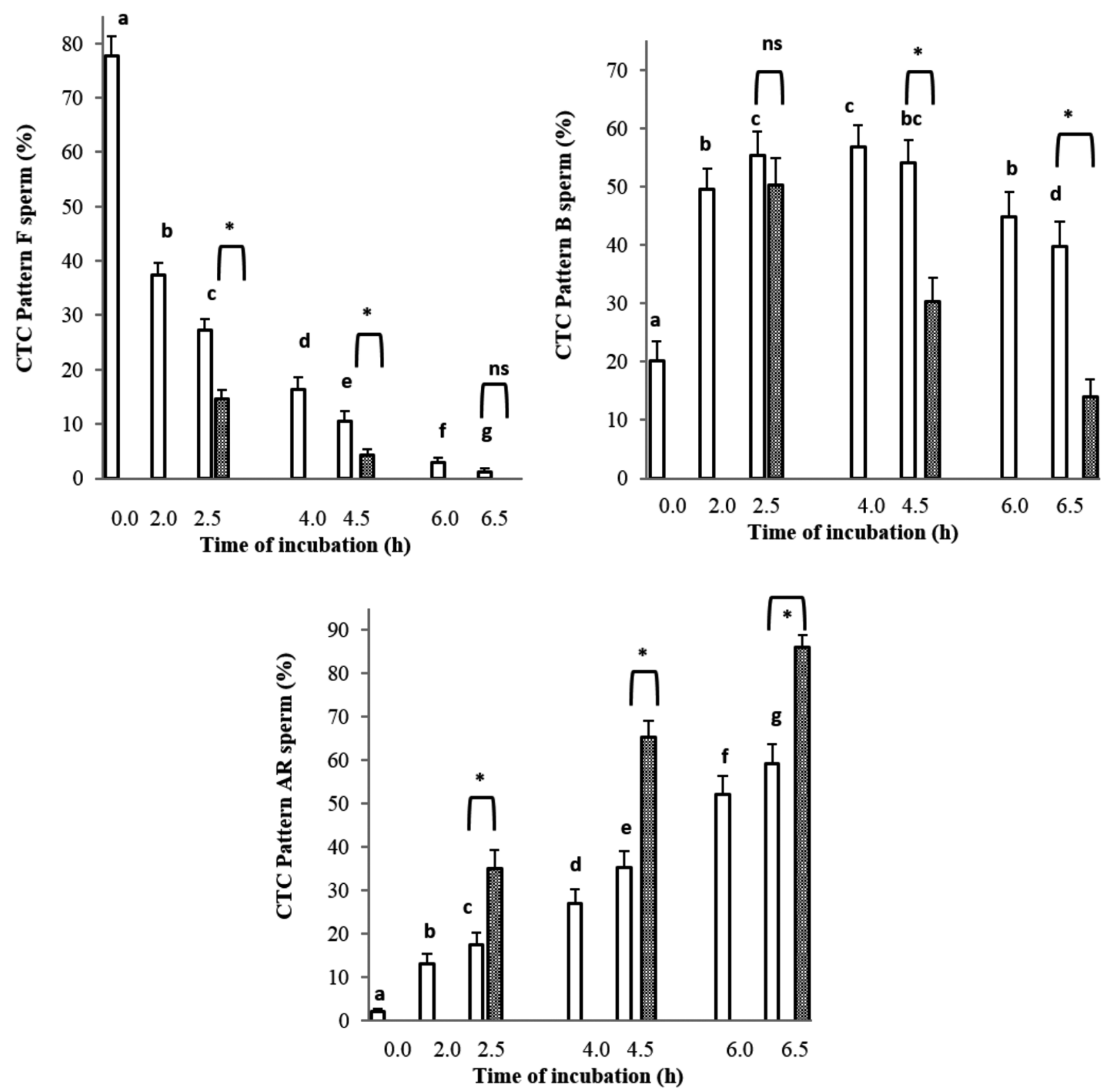

Figure 4. Capacitation status of dog spermatozoa incubated at $37{ }^{\circ} \mathrm{C}$ during $6.5 \mathrm{~h}$ under the effect of calcium ionophore. Values are means + SEM.

Control: open bars (a-g), calcium ionophore: shadowed bars.

Control vs calcium ionophore: $* P<0.05$, ns $=$ non significant.

EXPERIMENT 2. SPERM CRYOPRESERVATION AND POST-

\section{THAWING INCUBATION}

Stage 1. Sperm cryosurvival. After thawing, there was significant difference $(P<0.05)$ in the percentage of Merocyanine high-binding (hyper-fluidity) cells between sperm cooled to either $+5^{\circ} \mathrm{C}(69.5 \pm 3.30$ Mean \pm SEM $)$ or $-5{ }^{\circ} \mathrm{C}(63.8 \pm 3.00$ Mean $\pm \mathrm{SEM})$. There were no differences between cooling temperatures in the other sperm characteristics (table 1).
Stage 2. Induction of the acrosome reaction on cryopreserved dog spermatozoa. The number of acrosome-intact spermatozoa from $+5{ }^{\circ} \mathrm{C}$ and $-5{ }^{\circ} \mathrm{C}$ cooling treatments decreased as incubation progressed. At $4.5 \mathrm{~h}$ of incubation in each cooling treatment, there were differences between the control and the experimental groups $\left(\mathrm{CI}\right.$ and $\left.\mathrm{P}_{4}\right)$, but there was no difference between $\mathrm{CI}$ and $\mathrm{P}_{4}$ The number of plasma membrane-intact spermatozoa from $+5{ }^{\circ} \mathrm{C}$ and $-5^{\circ} \mathrm{C}$ cooling treatments decreased significantly $(P<0.05)$ as incubation progressed. However, at $4.5 \mathrm{~h}$ of incubation, 

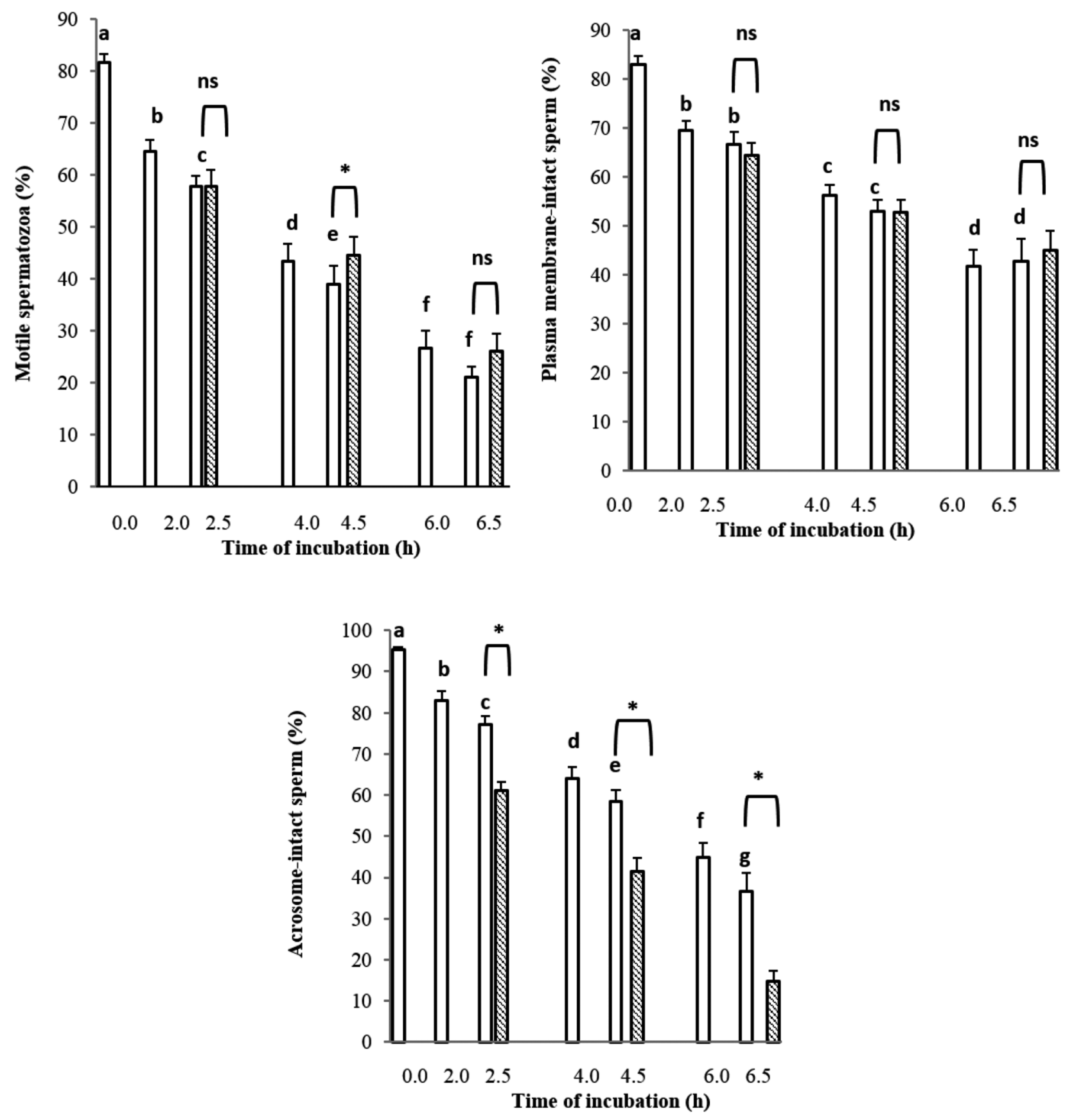

Figure 5. Motile, plasma membrane-intact, and acrosome-intact dog spermatozoa incubated at $38{ }^{\circ} \mathrm{C}$ in $5 \% \mathrm{CO}_{2}$ in air during $6.5 \mathrm{~h}$ under the effect of Progesterone. Values are means + SEM.

Control: open bars (a-g), Progesterone: shadowed bars.

Control vs Progesterone: $* P<0.05$, ns $=$ non significant.

there were no differences between the control, $\mathrm{CI}$ and $\mathrm{P}_{4}$ of each cooling treatment. Figure 7 comparatively shows the percentages of acrosome-intact and plasma membrane-intact spermatozoa from $+5{ }^{\circ} \mathrm{C}$ and $-5{ }^{\circ} \mathrm{C}$ cooling treatments. There were no differences in any pair of values $\left(+5^{\circ} \mathrm{C}\right.$ vs. $-5{ }^{\circ} \mathrm{C}$ ) incubated at the same time with an inductor of the acrosome reaction ( $\mathrm{CI} \& \mathrm{P}_{4}$ ) or without (control).

\section{DISCUSSION}

This work was conducted to compare the effect of 2 pre-freeze cooling temperatures, $+5^{\circ} \mathrm{C}$ vs. $5^{\circ} \mathrm{C}$, on the in vitro fertilising capacity of cryopreserved dog spermatozoa assessed by the sperm capacity to perform the acrosome reaction, $\mathrm{CI}$ and $\mathrm{P}_{4}$. In the first experiment, the induction 
Table 1. Effect of cooling to $+5^{\circ} \mathrm{C}$ and $-5^{\circ} \mathrm{C}$ before freezing on dog sperm cryosurvival.

\begin{tabular}{|c|c|c|c|c|c|c|c|}
\hline \multirow{2}{*}{$\begin{array}{l}\text { Cooling target } \\
\text { temperature }\end{array}$} & \multirow{2}{*}{$\begin{array}{c}\text { Progressive } \\
\text { motility } \\
(\%)\end{array}$} & \multirow{2}{*}{$\begin{array}{c}\text { MC540 } \\
\text { high-binding } \\
\text { cells } \\
(\%)\end{array}$} & \multirow{2}{*}{$\begin{array}{l}\text { Acrosome } \\
\text { integrity } \\
(\%)\end{array}$} & \multicolumn{3}{|c|}{$\begin{array}{l}\text { Capacitation status } \\
\text { (CTC patters \%) }\end{array}$} & \multirow{2}{*}{$\begin{array}{c}\text { Plasma membrane } \\
\text { integrity }(\%)\end{array}$} \\
\hline & & & & $\mathrm{F}$ & B & $\mathrm{AR}$ & \\
\hline$+5^{\circ} \mathrm{C}$ & $30.0 \pm 3.09$ & $69.5 \pm 3.30^{\mathrm{a}}$ & $80.9 \pm 0.99$ & $11.4 \pm 1.21$ & $73.4 \pm 1.29$ & $15.2 \pm 0.82$ & $34.0 \pm 2.68$ \\
\hline$-5^{\circ} \mathrm{C}$ & $28.7 \pm 2.15$ & $63.8 \pm 3.00^{\mathrm{b}}$ & $82.3 \pm 0.95$ & $12.5 \pm 0.90$ & $73.4 \pm 1.00$ & $14.1 \pm 0.91$ & $36.3 \pm 2.79$ \\
\hline
\end{tabular}

Values are Means \pm SEM. Different letters in columns indicate significant differences $(\mathrm{p}<0.05)$. Progressive motility, visual; plasma membrane fluidity, merocyanine (MC540); acrosome integrity, PSA-FITC; capacitation status, CTC assay; plasma membrane integrity, SYBR14/PI.
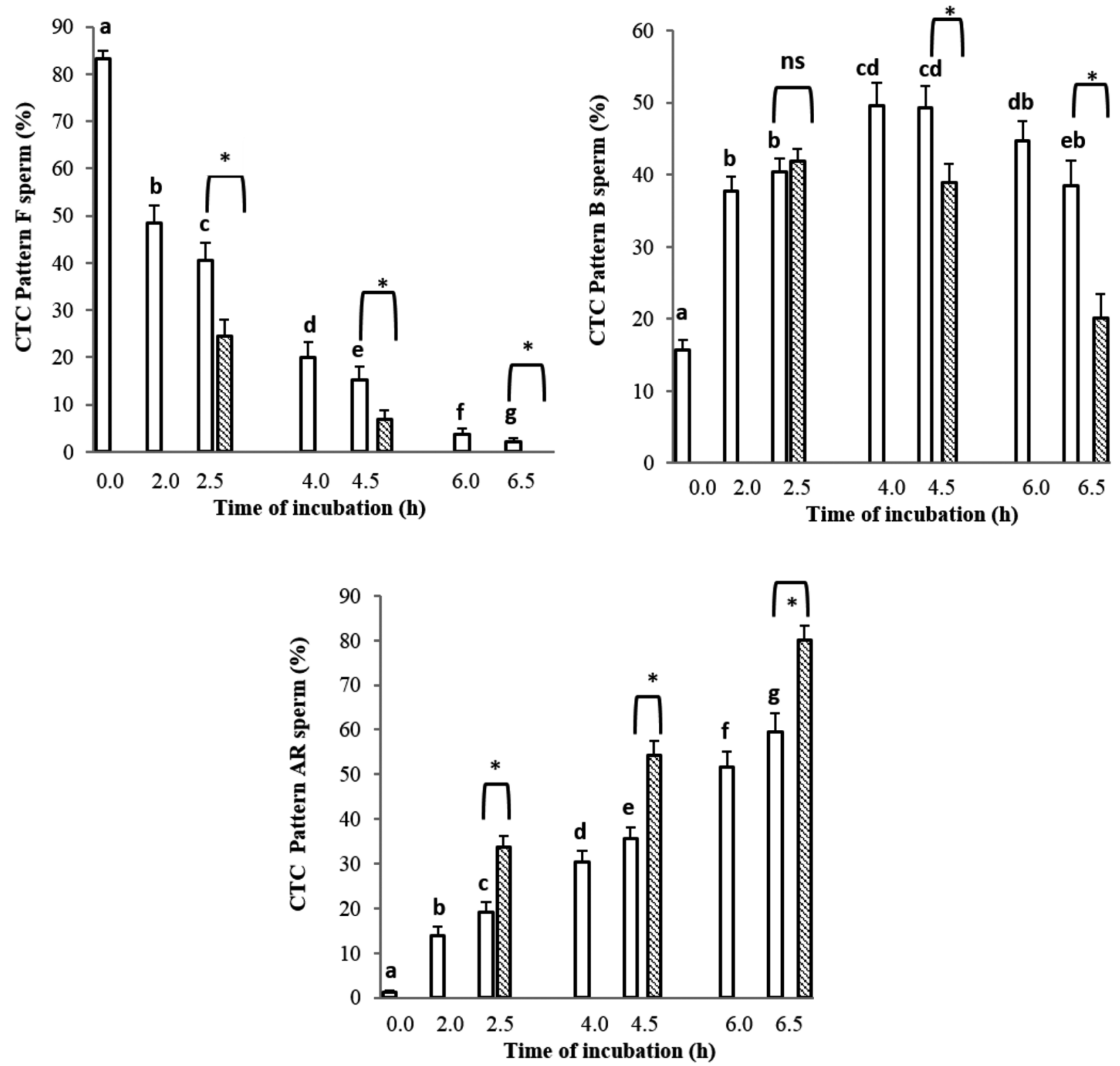

Figure 6. Capacitation status of dog spermatozoa incubated at $38{ }^{\circ} \mathrm{C}$ in $5 \% \mathrm{CO}_{2}$ in air during $6.5 \mathrm{~h}$ under the effect of Progesterone. Values are means + SEM.

Control: open bars (a-g), Progesterone: shadowed bars.

Control vs Progesterone: $* P<0.05$, ns $=$ non significant. 

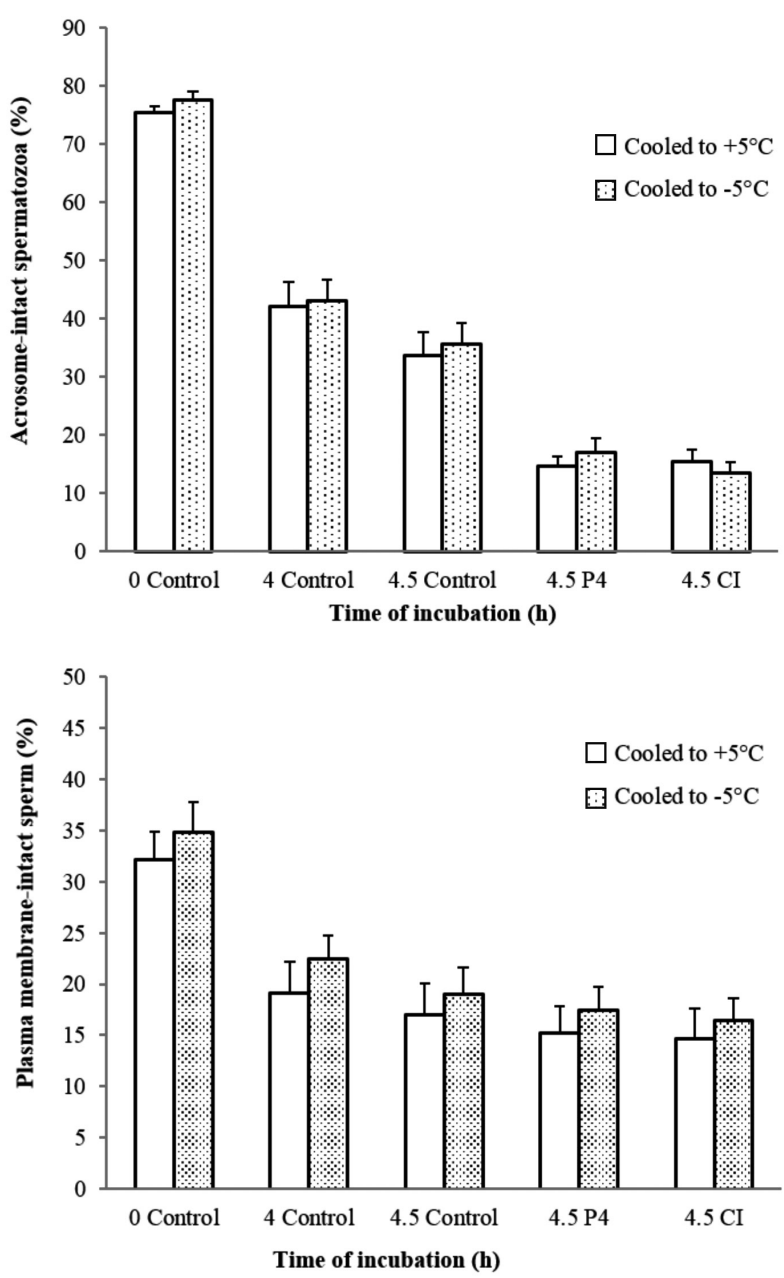

Figure 7. Acrosome-intact and plasma membrane-intact dog spermatozoa after freeze-thawing and post-thaw incubation for $4.5 \mathrm{~h}$ at $38{ }^{\circ} \mathrm{C}$ in $5 \% \mathrm{CO}_{2}$ in air, without or with Progesterone (P4)/Calcium ionophore, to induce the acrosome reaction. Sperm were colled to two target temperatures before freezing: $+5^{\circ} \mathrm{C}$ or $-5^{\circ} \mathrm{C}$ Values are means \pm SEM.

of acrosome reaction in fresh-incubated spermatozoa using $\mathrm{CI}$ and $\mathrm{P}_{4}$ was validated. Taking into account CTC capacitation patterns (i.e., $\mathrm{B}$ and $\mathrm{AR}$ ) and the acrosome status, 4 and $4.5 \mathrm{~h}$ of incubation were chosen as the optimun time of incubation for the sperm to display the acrosome reaction. Thus, in the next experiments, those times of incubation were used.

The second experiment assessed sperm cryosurvival. One important finding was that after thawing, there was a significant difference in the number of Merocyanine high-binding (hyper-fluidity) cells between sperm cooled to either $+5^{\circ} \mathrm{C}$ or $-5^{\circ} \mathrm{C}$, with the value of the former larger than that of the latter. This observation agrees with the proposed hypothesis that cooling of spermatozoa to sub-zero temperatures, around the freezing point (of diluted spermatozoa), favours sperm plasma membrane reorganisation after lipid phase transition takes place, thus avoiding an excessive increase of membrane fluidity (Watson 1995, Holt
2000). We are aware that this hypothesis disagrees with the general concept that an increase in membrane fluidity before freezing favours sperm cryosurvival (Giraud et al 2000, Aboagla and Terada 2003). Increased plasma membrane fluidity may benefit some sperm characteristics, such as motility (Giraud et al 2000), but also seems to be related to the incidence of premature sperm capacitation (Watson 1995). In physiological conditions, plasma membrane fluidity increases during sperm capacitation to prepare sperm membranes to suffer the acrosome reaction and facilitates the sperm-oocyte interaction (Flesch and Gadella 2000); however, in cryopreserved sperm, hyper-fluidity shortens the window of sperm fertility (Watson 1995). Studying the cryopreservation of dog spermatozoa, Alcantar-Rodriguez and Medrano (2017) found no differences in sperm quality and plasma membrane fluidity between sperm cooled to either $+5{ }^{\circ} \mathrm{C}$ or $-5^{\circ} \mathrm{C}$. In that work, approximately $52 \%$ of spermatozoa were classified as Merocyanine high-binding cells (hyper-fluidity). In contrast, in our work, values were 69.5 and $63.8 \%$ for $+5{ }^{\circ} \mathrm{C}$ and $-5{ }^{\circ} \mathrm{C}$, respectively. In the study by Alcantar-Rodriguez and Medrano (2017), sperm were frozen on the next day after collection. In contrast, in our work sperm were collected and frozen on the same day. Thus, it could be the long storage at $+5{ }^{\circ} \mathrm{C}$ and the stress of cryopreservation itself that minimised any positive effect of cooling to sub-zero temperatures on dog sperm fluidity. Plasma membrane fluidity may be modified during cryopreservation by both removal of cholesterol from the plasma membrane and by lipid peroxidation (Moein-Vaziri et al 2014), however, in our work, we were not able to discriminate between these 2 mechanisms.

Regarding the induction of the acrosome reaction on frozen-thawed spermatozoa, there were no differences between $\mathrm{CI}$ and $\mathrm{P}_{4}$ or between cooling temperatures $\left(+5^{\circ} \mathrm{C}\right.$ or $-5^{\circ} \mathrm{C}$ ) in the proportion of spermatozoa that carried out that process. $\mathrm{CI}$ and $\mathrm{P}_{4}$ have been previously used to induce the acrosome reaction in fresh and cryopreserved dog spermatozoa (Szász et al 2000, Cheng et al 2005), however, to our knowledge, CI and P4 have not been comparatively used in frozen-thawed dog spermatozoa. In our work, both induced the AR after $4.5 \mathrm{~h}$ of incubation; thus, either of them may be employed for that purpose in future research.

In this work, we partially proved our hypothesis that cooling of spermatozoa to $-5{ }^{\circ} \mathrm{C}$ favours sperm plasma membrane reorganisation, thus avoiding an excessive increase of plasma membrane fluidity. The membrane phase behaviour of different cellular types (human prostate tumour cells, porcine smooth muscle cells and human dermal fibroblasts) during freezing seems to depend on the ice nucleation temperature (Balasubramanian et al 2009). In these cellular types, membrane phase transition causes different effects on the membrane conformational disorder in the frozen state when the ice nucleation occurs at either $-3{ }^{\circ} \mathrm{C}$ (favours dehydration) or $-10{ }^{\circ} \mathrm{C}$ (intracellular ice formation). Balasubramanian et al (2009) reported that ice nucleation at $-6{ }^{\circ} \mathrm{C}$ (between temperature for dehydration 
and that for intracellular ice formation) enables a fraction of cellular and membrane bound water to stay in the cell and thus promotes cell viability. This may be the mechanism by which cooling to $-5^{\circ} \mathrm{C}$ before freezing favours sperm cryosurvival.

At this point, we do not know whether cooling to sub-zero temperatures improves the fertilising capacity of frozen-thawed dog spermatozoa. A test of fertility by artificial insemination employing cryopreserved spermatozoa would provide further insights on that issue. It should also be considered that semen from different dog breeds may show variations in sperm cryosurvival when freeze-thawing protocols are modified (Yu et al 2002).

In conclusion, cooling to $-5^{\circ} \mathrm{C}$ did not improve dog sperm cryosurvival but produced a positive effect of plasma membrane fluidity, and the amount of Merocyanine high-binding (hyper-fluidity) cells was smaller than that of sperm cooled to $+5^{\circ} \mathrm{C}$.

\section{ACKNOWLEDGEMENTS}

This work was supported by the Universidad Nacional Autónoma de México under grants PAPIIT-IN213815, IA204917; PIAPI-1615.

\section{REFERENCES}

Aboagla EME, Terada T. 2003. Trehalose-enhanced fluidity of the goat sperm membrane and its protection during freezing. Biol Reprod 69, 1245-1250.

Alcantar-Rodriguez A, Medrano A. 2017. The effect of cooling to different subzero temperatures on dog sperm cryosurvival. Reprod Domest Anim 52, 422-428.

Balasubramanian SK, Wolkers WF, Bischof JC. 2009. Membrane hydration correlates to cellular biophysics during freezing in mammalian cells. Bioch Biophys Acta 1788, 945-953.

Cheng FP, Wu JT, Tsai PS, Chang CLT, Lee SL, et al. 2005. Effects of cryo-injury on progesterone receptor(s) of canine spermatozoa and its response to progesterone. Theriogenology 64, 844-854.

Contreras-Mendez LA, Medrano A. 2016. A comparative study of two cooling protocols on stallion sperm cryosurvival. Andrologia 48, 558-563.

Crowe JH, Hoekstra FA, Crowe LM, Anchordoguy TJ, Drobnis E. 1989. Lipid phase transitions measured in intact cells with Fourier transform infrared spectroscopy. Cryobiology 26, 76-84.

Eilts BE. 2005. Theoretical aspects of canine semen cryopreservation. Theriogenology 64, 692-697.

Feldman EC, Nelson RW. 1996. Clinical and diagnostic evaluation of the male reproductive tract. In: Feldman EC, Nelson RW (eds).
Canine and Feline Endocrinology and Reproduction. WB Saunders, Philadelphia, USA, Pp 673-690.

Flesch FM, Gadella BM. 2000. Dynamics of the mammalian sperm plasma membrane in the process of fertilization. Bioch Biophys Acta 1469, 197-235.

Garner DL, Johnson LA. 1995. Viability assessment of mammalian sperm using SYBR14 and propidium iodide. Biol Reprod 53, 276-284.

Garzon-Perez C, Flores HF, Medrano A. 2010. A simple osmotic stress test to predict boar sperm cryosurvival. CryoLetters 31, 438-444.

Giraud MN, Motta C, Boucher D, Grizard G. 2000. Membrane fluidity predicts the outcome of cryopreservation of human spermatozoa. Human Reprod 15, 2160-2164.

Graham JK, Foote RH. 1987. Dilaurylphosphatidyl-cholina liposomes effects on the acrosome reaction and in vitro penetration of zona-free hamster eggs by bull spermatozoa: A fertility assay for frozen-thawed semen. Gamete Res 16, 147-158.

Holt WV. 2000. Fundamental aspects of sperm cryobiology: the importance of species and individual differences. Theriogenology 53, 47-58.

Lucio CF, Brito MM, Angrimani DSR, Belaz KRA, Morais D, et al. 2017. Lipid composition of the canine sperm plasma membrane as markers of sperm motility. Reprod Dom Anim 52 (Suppl. 2), 208-213.

Medrano A, Holt WV, Watson PF. 2009. Controlled freezing studies on boar sperm cryopreservation. Andrologia 41, 246-250.

Moein-Vaziri N, Phillips I, Smith S, Almiñana C, Maside C, et al. 2014. Heat-shock protein A8 restores sperm membrane integrity by increasing plasma membrane fluidity. Reproduction 147, 719-732.

Peña A, Linde Forsberg C. 2000. Effects of Equex, one-or two-step dilution, and two freezing and thawing rates on post-thaw survival of dog spermatozoa. Theriogenology 54, 859-875.

Rota A, Peña AI, Linde-Forsberg C, Rodriguez-Martinez H. 1999. In vitro capacitation of fresh, chilled and frozen-thawed dog spermatozoa assessed by chlortetracycline assay and changes in motility patterns. Anim Reprod Sci 57, 199-215.

Snedecor GW, Cochran WG. 1989. Statistical Methods. $8^{\text {th }}$ ed. Iowa State University Press, Ames, USA.

Steckler D, Stout TAE, Durant C, Nothling JO. 2015. Validation of merocyanine 540 staining as a technique for assessing capacitation-related membrane destabilization of fresh dog sperm. Theriogenology 83, 1451-1460.

Szász F, Sirivaidyapong S, Cheng FP, Marks A, Voorhout WF, et al. 2000. Detection of calcium ionophore induced membrane changes in dog sperm as a simple method to predict the cryopreservability of dog semen. Mol Reprod Dev 55, 289-298.

Watson PF. 1995. Recent developments and concepts in the cryopreservation of spermatozoa and the assessment of their post-thawing function. Reprod Fert Dev 7, 871-891.

Whitfield CH, Parkinson TJ. 1992. Relationship between fertility of bovine semen and in vitro induction of acrosome reactions by heparin. Theriogenology 38, 11-20.

Yu I, Songsasen N, Godke RA, Leibo SP. 2002. Differences among dogs in response of their spermatozoa to cryopreservation using various cooling and warming rates. Cryobiology 44, 62-78. 